\title{
Hyperalgesic effect induced by barbiturates, midazolam and ethanol: pharmacological evidence for GABA-A receptor involvement
}

M.A.K.F. Tatsuo,

C.M. Yokoro, J.V. Salgado,

S.M.S. Pesquero,

M.A.P. Santana and

J.N. Francischi
Departamento de Farmacologia, Instituto de Ciências Biológicas,

Universidade Federal de Minas Gerais, 31270-100 Belo Horizonte, MG, Brasil

\section{Correspondence \\ M.A.K.F. Tatsuo \\ Departamento de Farmacologia ICB, UFMG \\ Av. Antônio Carlos, 6627 \\ 31270-100 Belo Horizonte, MG \\ Brasil}

Research supported by FAPEMIG (CBS No. 493/90) and PRPq

(Universidade Federal de

Minas Gerais, Brasil).

$\ldots \ldots \ldots \ldots \ldots \ldots$

Received January 23, 1996 Accepted November 11, 1996

\begin{abstract}
The involvement of GABA-A receptors in the control of nociception was studied using the tail-flick test in rats. Non-hypnotic doses of the barbiturates phenobarbital $(5-50 \mathrm{mg} / \mathrm{kg})$, pentobarbital $(17-33 \mathrm{mg} /$ $\mathrm{kg}$ ), and thiopental $(7.5-30 \mathrm{mg} / \mathrm{kg})$, of the benzodiazepine midazolam $(10 \mathrm{mg} / \mathrm{kg})$ or of ethanol $(0.4-1.6 \mathrm{~g} / \mathrm{kg})$ administered by the systemic route reduced the latency for the tail-flick response, thus inducing a 'hyperalgesic' state in the animals. In contrast, non-convulsant doses of the GABA-A antagonist picrotoxin $(0.12-1.0 \mathrm{mg} / \mathrm{kg})$ administered systemically induced an increase in the latency for the tail-flick response, therefore characterizing an 'antinociceptive' state. Previous picrotoxin $(0.12 \mathrm{mg} / \mathrm{kg})$ treatment abolished the hyperalgesic state induced by effective doses of the barbiturates, midazolam or ethanol. Since phenobarbital, midazolam and ethanol reproduced the described hyperalgesic effect of GABA-A-specific agonists (muscimol, THIP), which is specifically antagonized by the GABA-A antagonist picrotoxin, our results suggest that GABA-A receptors are tonically involved in the modulation of nociception in the rat central nervous system.
\end{abstract}

Key words - Barbiturates

- Midazolam

- Ethanol

- Picrotoxin

- Hyperalgesia

- GABA-A receptor

\section{Introduction}

Barbiturates, benzodiazepines and ethanol, although belonging to chemically distinct classes of drugs, share some pharmacological properties. The principal medical indication of the barbiturate phenobarbital is the prevention of grand mal epilepsy (1), whereas the benzodiazepine midazolam is used as a pre-anesthetic medication (2). Etha- nol is more a sociological than a medical problem due to its risk of abuse (3). However, all three drugs induce a general depressant effect in the central nervous system (CNS).

Barbiturates, midazolam and ethanol have been shown to increase the inhibitory $\gamma$-aminobutyric acid (GABA) transmission which leads to the CNS depression mentioned above (4-6). At the molecular level, 
barbiturates and benzodiazepines potentiate GABA actions by a) prolonging the open state of the chloride-associated channels and by b) increasing the frequency of opening of the chloride channels, respectively. These effects can be competitively antagonized by bicuculline or non-competitively by picrotoxin $(4,5)$.

Many reports in the literature have shown the involvement of GABA receptors in the modulation of nociception in the central nervous system (4). Administration of GABAA agonists seems to interfere with nociception, whereas the GABA-B agonist baclofen can induce analgesia at spinal or supraspinal levels (4). Recent reports in the literature have suggested the involvement of the GABA-A receptor in the modulation of central nociception through the descending inhibitory system (7).

Experimentally, GABA-A agonists such as muscimol and THIP (4,5,6,7-tetrahydroisoxal-[5,4-c]-pyridin-3-ol) injected into the rostral ventromedial medulla (RVM) induced hyperalgesia, as detected by the tailflick method (8). Hyperalgesia was also detected after muscimol microinjection into the periaqueductal grey matter (PAG) as shown by Zambotti et al. (9), Moreau and Fields (10), and Behbehani et al. (11). As expected, the GABA antagonists bicuculline and picrotoxin present antinociceptive effects whether microinjected into the RVM, PAG (10) or the lateral ventricles (8). In addition, systemic bicuculline or picrotoxin administration induces an antinociceptive effect per se or prior to microinjection of GABA-A agonists into the RVM (8) or the PAG (11). Hyperalgesia or no effect has also been described following injection of bicuculline or picrotoxin into the spinal medulla (12). However, the controversy about whether barbiturates and benzodiazepines are analgesic or hyperalgesic is still unsolved. Hyperalgesia as well as analgesia have been reported following administration of both drugs to humans or rodents (13-19).
The aim of the present study was to determine the effect of systemic administration of the barbiturates phenobarbital, pentobarbital and thiopental, the benzodiazepine midazolam, and ethanol using the tail-flick model in rats. In addition, picrotoxin alone or in association with these agonists was also used to assess the potential role of the GABA-A receptor in the tail-flick response.

\section{Material and Methods}

\section{Animals}

Male Holtzman rats weighing 180-250 g were used. The animals were housed at a temperature of $24 \pm 2^{\circ} \mathrm{C}$, with food and water ad libitum and a 12-h light-dark cycle for 24 $\mathrm{h}$ before the experiments.

\section{Measurement of pain threshold}

A slight modification of the method described by D'Amour and Smith (20) was used to detect the tail-flick response. Briefly, a voltimeter and an amperimeter were connected to the system to permit variation of the resistance heating. Stimuli of $0.31 \mathrm{cal} /$ sec caused a 3.5-4.5-sec latency for the tailflick baseline in the rats. Test tail-flick responses in duplicate at 10, 20, 30, 40 and 60 min following drug administration are reported as tail-flick index (TFI). The TFI was the percent of the maximum response obtained before and after drug administration to the animals, as expressed in the following formula:

$\mathrm{TFI}=\frac{\text { Post-drug latency }(\mathrm{sec})-\text { baseline latency }(\mathrm{sec})}{7 \mathrm{sec}-\text { baseline latency }} \times 100$

Under our conditions, the cut-off time was defined as $7 \mathrm{sec}$ (in the formula). The mean area under the various TFI curves $(\mathrm{AUC}) \pm \mathrm{SEM}$ from control and drug-treated animals was also obtained. Positive and negative values indicated analgesia and hyperalgesia, respectively, for both TFI and AUC. 


\section{Drug treatments}

The barbiturates and midazolam, diluted in propylene glycol:saline (50:50, v/v) and in manufacturer-supplied vehicle, respectively, were administered by the intraperitoneal (ip) route in a volume of $0.1 \mathrm{ml} / \mathrm{kg}$. Ethanol was diluted in physiological saline and administered orally $(0.2 \mathrm{ml} / \mathrm{kg})$ rather than ip to prevent peritoneal irritation. Picrotoxin diluted in physiological saline was administered ip alone or $10 \mathrm{~min}$ before the injection of agonists. In these experiments, control animals received vehicle or saline $(0.1 \mathrm{ml} / 100 \mathrm{~g})$ either ip or orally.

\section{Drugs}

The following drugs were purchased from the stated sources: phenobarbital (Rhodia, Santo Amaro, SP), pentobarbital (Cristalia, Itapira, SP), thiopental (Abbott, São Paulo, $\mathrm{SP})$, midazolam (Roche, Rio de Janeiro, RJ), ethanol (Grupo Química, Rio de Janeiro, RJ), picrotoxin (Sigma Chemical Co., St. Louis, MO), and propylene glycol (Reagen, Rio de Janeiro, RJ).

\section{Statistical analysis}

The results are reported as mean \pm SEM. Data for the time-effect curve were subjected to multivariate analysis of variance (MANOVA). In case of interaction between treatment and time, MANOVA was followed by one-way analysis of variance (ANOVA) for each time. For the analysis of the treatment effect only, MANOVA was followed by ANOVA for the area under the curve. For multiple comparisons, ANOVA was followed by the Duncan test. Statistical significance was accepted at $\mathrm{P}<0.05$.

\section{Results}

Intraperitoneal administration of phenobarbital $(5-50 \mathrm{mg} / \mathrm{kg})$, pentobarbital (17-33
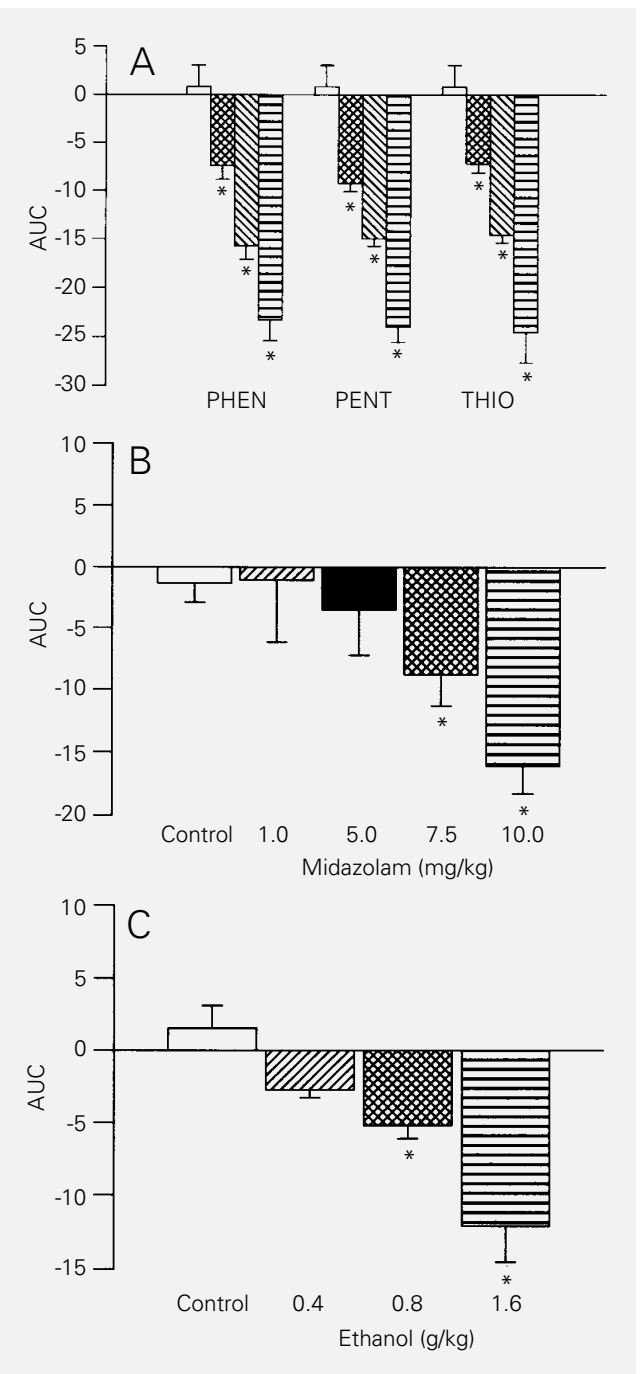

$\mathrm{mg} / \mathrm{kg}$ ) and thiopental $(7.5-30 \mathrm{mg} / \mathrm{kg}) \mathrm{re}-$ duced the latency for the tail-flick response in rats in a dose-dependent manner, therefore inducing hyperalgesia, as shown in Figure 1A. Doses higher than 50, 33 and $30 \mathrm{mg} /$ kg phenobarbital, pentobarbital and thiopental, respectively, induced hypnotic effects in the rats, thus precluding the use of these doses in our experiments (data not shown). Significant hyperalgesia was observed 10 min after barbiturate administration, with a maximal effect being detected at $30 \mathrm{~min}$, and remained significantly elevated for the subsequent $30 \mathrm{~min}$ of observation, as illustrated for $20 \mathrm{mg} / \mathrm{kg}$ phenobarbital in Figure 2A. This effect was observed with the three bar-
Figure 1 - Dose-response curves for barbiturate- (A), midazolam(B) and ethanol- (C) induced hyperalgesia in rats using the tailflick method. Increasing doses of the barbiturates phenobarbital (PHEN, 5, 20 and $50 \mathrm{mg} / \mathrm{kg}$, ip), pentobarbital (PENT, 17, 25 and $33 \mathrm{mg} / \mathrm{kg}$, ip), thiopental (THIO, 7.5, 15 and $30 \mathrm{mg} / \mathrm{kg}$, ip) , midazolam (1-10 mg/kg, ip) and ethanol $(0.4-1.6 \mathrm{~g} / \mathrm{kg}$, oral) were administered $10 \mathrm{~min}$ before the test. Control animals (open column) received vehicles (propylene glycol:saline, 50:50, v/v) ip or oral saline. The results are expressed as mean area under the tail-flick index (TFI) curves (AUC) \pm SEM for 8 experiments. Hyperalgesia is represented by negative values on the ordinate. ${ }^{*} \mathrm{P}<0.05$ compared to control (one-way analysis of variance). 
Figure 2 - Picrotoxin blocked the hyperalgesia induced by systemic phenobarbital (A), midazolam (B) or ethanol (C) administration to rats. Picrotoxin was administered ip 20 min before the tail-flick test. The agonists phenobarbital $(20 \mathrm{mg} / \mathrm{kg}, i p)$, midazolam $(10 \mathrm{mg} / \mathrm{kg}$, ip) or ethanol $(1.6 \mathrm{~g} / \mathrm{kg}$, oral) were administered $10 \mathrm{~min}$ before the test. Control animals were injected ip or orally treated with the respective vehicles. Each point indicates the mean \pm SEM of the data from 8 rats. Hyperalgesia is indicated by the negative values on the ordinate; positive values indicate antinociception. ${ }^{*} \mathrm{P}<0.05$ compared to control (Duncan test). TFI, Tail-flick index.
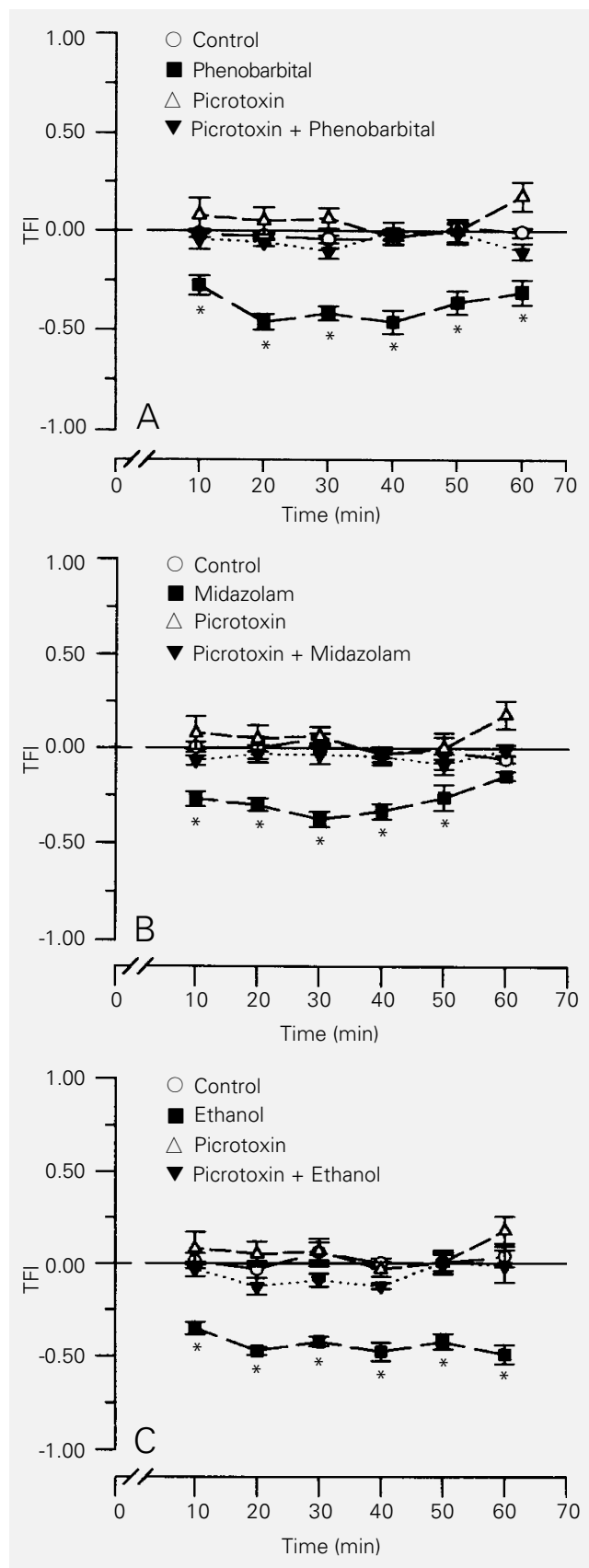

biturates in the dose range used (data not shown). However, barbiturate-induced hyperalgesia was significantly reduced $2 \mathrm{~h}$ after drug administration at the higher dose used (data not shown). In addition, midazolam $(1.0-10 \mathrm{mg} / \mathrm{kg})$ and ethanol $(0.4-1.6 \mathrm{~g} /$ $\mathrm{kg}$ ) also induced a dose-dependent hyperalgesia (Figure 1B and C, respectively), which showed a similar profile to that observed for
$20 \mathrm{mg} / \mathrm{kg}$ phenobarbital (Figure 2A). Different from phenobarbital, however, midazolam induced a hyperalgesia of shorter duration (50 min), whereas ethanol-induced hyperalgesia was detected at $10 \mathrm{~min}$ of drug administration and had a longer duration $(2 \mathrm{~h}$; data not shown). Administration of the various vehicles used did not induce a significant variation in the latency of the tail-flick response presented by the animals (control in Figures 1, 2 and 3).

Intraperitoneal picrotoxin injection $(0.12-$ $1.0 \mathrm{mg} / \mathrm{kg}$ ) induced a dose-dependent increase in the latency for the tail-flick response in rats, which characterized an antinociceptive effect (Figure 3). However, at the lower dose of $0.12 \mathrm{mg} / \mathrm{kg}$, picrotoxin was not able to induce an antinociceptive effect per se, although it could inhibit the hyperalgesic effect induced by phenobarbital, midazolam and ethanol (Figure 2A, B and C, respectively).

\section{Discussion}

The precise effect of the administration of barbiturates or benzodiazepines on the mechanisms of pain modulation in humans or rats is still controversial. Analgesia, hyperalgesia or no effect has been attributed to these drugs (13-19).

In the present study, we have shown that systemic administration of non-hypnotic doses of the barbiturates phenobarbital, pentobarbital and thiopental induced a dosedependent hyperalgesia, as measured by the reduction of the latency for the tail-flick response in rats. Interestingly, non-hypnotic doses of the benzodiazepine midazolam and of ethanol systemically administered also induced a dose-dependent hyperalgesia using the same method.

Barbiturates, benzodiazepines and ethanol are known to be agonists of the GABAA receptor complex which are ubiquitously distributed throughout the CNS, including the descendent inhibitory system $(7,21)$. A 
facilitating action of the inhibitory neurotransmitter $\gamma$-aminobutyric acid (GABA) on the GABA-A receptor by these drugs could ultimately favor the expression of an inhibitory effect on the descending inhibitory system, with a consequent hyperalgesic behavior. This hypothesis was further reinforced by the observed blockade of the hyperalgesia induced by the association of barbiturates, midazolam or ethanol with a low dose of the GABA-A antagonist picrotoxin and a clear-cut antinociceptive effect with higher doses of picrotoxin. If this is so, these results also indicate that there is a GABAergic tonus in the descendent inhibitory system.

The use of bicuculline, the specific antagonist of GABA-A receptor, also blocked the hyperalgesia induced by these agonists using the tail-flick test (Yokoro CM and Tatsuo MAKF, unpublished observations). A general depressant effect induced by these drugs at higher doses might obscure this hyperalgesic effect, thus explaining the analgesia or absence of effect formerly related to these drugs in the reported studies (18).

In the present study, however, association of various doses of picrotoxin with midazolam only blocked the hyperalgesic effect induced by the latter, without displaying an analgesic response as observed with barbiturates and ethanol (data not shown). It has been described that the binding site of midazolam is distant from that at which barbiturates or ethanol interact with the GABA-A receptor $(21,22)$. It is possible that the binding of barbiturates or ethanol could facilitate

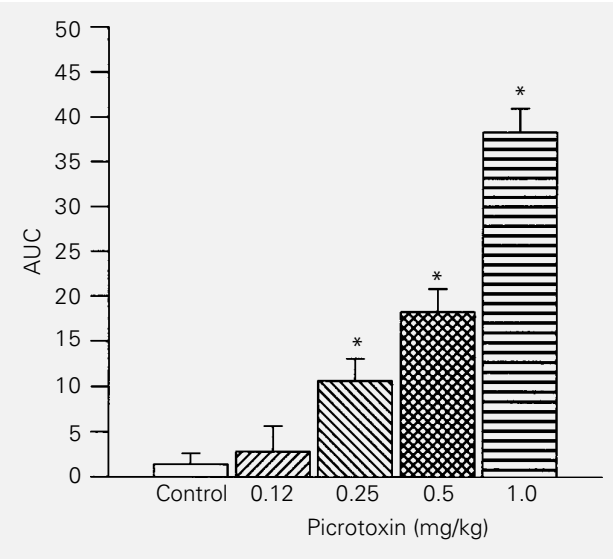

the close association of picrotoxin at the GABA-A receptor, which ultimately leads to the inhibition of the neurotransmitter action. In our experiments, this inhibitory effect was translated as an antinociceptive effect. Midazolam, in turn, interacting with another site, such as the $\alpha$-subunit of the GABA-A receptor (21), did not display this effect.

Our data demonstrate the involvement of the GABA-A receptor in the modulation of pain pathways. It is suggested that the allosteric change of this receptor induced by barbiturates and ethanol is different from that induced by midazolam, since the association of the latter with picrotoxin did not display the antinociceptive effect observed in the association of the former drugs with picrotoxin. We suggest that this hyperalgesic effect should be taken into account in cases of barbiturate use or ethanol intoxication, since non-hypnotic doses of these drugs are used under such conditions.
Figure 3 - Picrotoxin induced a dose-dependent antinociception in rats, as measured by the tailflick method. Picrotoxin $(0.12$ $1.0 \mathrm{mg} / \mathrm{kg}$ ) was administered by the intraperitoneal route $20 \mathrm{~min}$ before the test. ${ }^{*} P<0.05 \mathrm{com}-$ pared to control (one-way analysis of variance). AUC, Area under the tail-flick index curve.

\section{References}

1. Rall TW \& Schleifer LS (1990). Drugs effective in the therapy of the epilepsies. In: Goodman Gilman A, Rall TW, Nies AS \& Taylor P (Editors), The Pharmacological Basis of Therapeutics. MacMillan, New York, 436-462.
2. Marshall BE \& Longnecker DE (1990). General anesthetics. In: Goodman Gilman A, Rall TW, Nies AS \& Taylor P (Editors), The Pharmacological Basis of Therapeutics. MacMillan, New York, 285-331.

3. Rall TW (1990). Hypnotics and sedative; ethanol. In: Goodman Gilman A, Rall TW, Nies AS \& Taylor P (Editors), The Pharmacological Basis of Therapeutics. MacMillan, New York, 345-382.
4. Matsumoto RR (1989). GABA receptors: are cellular differences reflected in function? Brain Research Reviews, 14: 203225.

5. Reynolds JN, Prasad A \& MacDonald JF (1992). Ethanol modulation of GABA receptor-activated $\mathrm{Cl}^{-}$currents in neurons of the chick, rat and mouse central nervous system. European Journal of Pharmacology, 234: 173-181. 
6. Ticku MK \& Kulkarni SK (1988). Molecular interactions of ethanol with GABAergic system and potential of Ro 15-4513 as an ethanol antagonist. Pharmacology, Biochemistry and Behavior, 30: 501-510.

7. Fields $\mathrm{HL}$, Heinricher $M M$ \& Mason $P$ (1991). Neurotransmitters in nociceptive modulatory circuits. Annual Review of Neuroscience, 14: 219-245.

8. Heinricher MM \& Kaplan HJ (1991). GABA-mediated inhibition in rostral ventromedial medulla: role in nociceptive modulation in the lightly anesthetized rat. Pain, 47: 105-113.

9. Zambotti F, Zonta N, Parenti M, Tammiso $R$, Vicentini L, Conci F \& Mantegazza $P$ (1982). Periaqueductal matter involvement in the muscimol-induced decrease of morphine antinociception. NaunynSchmiedeberg's Archives of Pharmacology, 318: 368-369.

10. Moreau J-L \& Fields HL (1986). Evidence for GABA involvement in midbrain control of medullary neurons that modulate nociceptive transmission. Brain Research, 397: 37-46.
11. Behbehani MM, Jiang $M$, Chandler SD \& Ennis M (1990). The effect of GABA and its antagonists on midbrain periaqueductal gray neurons in the rat. Pain, 40: 195204.

12. Ueda H, Ge M, Satoh M \& Takagi H (1987). Subconvulsive doses of intracisternal bicuculline methiodide, a GABA-A receptor antagonist, produce potent analgesia as measured in the tail pinch test in mice. European Journal of Pharmacology, 136: 129-131.

13. Davidovich $S$, Niv D, Geller E \& Urca G (1988). Ro 15-1788 produces naloxonereversible analgesia in the rat. European Journal of Pharmacology, 146: 175-179.

14. Dundee JW (1960). Alterations in response to somatic pain associated with anaesthesia. II. The effect of thiopentone and pentobarbitone. British Journal of Anaesthesia, 32: 407-414.

15. González-Darder JM, Ortega-Alvaro A, Ruz-Franzi I \& Segura-Pastor D (1992). Antinociceptive effects of phenobarbital in "tail-flick" test and deafferentation pain. Anesthesia and Analgesia, 75: 8186.
16. Neal MJ (1965). The hyperalgesic action of barbiturates in mice. British Journal of Pharmacology, 24: 170-177.

17. Niv D, Davidovich S, Geller E \& Urca G (1988). Analgesic and hyperalgesic effects of midazolam: dependence on route of administration. Anesthesia and Analgesia, 67: 1169-1173.

18. Stein C, Morgan MM \& Liebeskind JC (1987). Barbiturate-induced inhibition of a spinal nociceptive reflex: role of GABA mechanisms and descending modulation. Brain Research, 407: 307-311.

19. Zambotti F, Zonta N, Tammiso R, Conci F, Hafner B, Zecca L, Ferrario P \& Mantegazza P (1991). Effects of diazepam on nociception in rats. NaunynSchmiedeberg's Archives of Pharmacology, 344: 84-89.

20. D'Amour FE \& Smith DL (1941). A method for determining loss of pain sensation. Journal of Pharmacology and Experimental Therapeutics, 72: 74-79.

21. MacDonald RL \& Olsen RW (1994). GABA-A receptor channels. Annual Review of Neuroscience, 17: 567-602.

22. Sieghart W (1995). Structure and pharmacology of $\gamma$-aminobutyric acid $_{A}$ receptor subtypes. Pharmacological Reviews, 47: 181-234. 